halogens too, makes reasonable to postulate decomposition in solution, $\mathrm{Me}_{4}$ bitt ${ }^{2+} 2 X^{-} \ldots \mathrm{Me}_{4} \mathrm{tms}+X_{2}$. Although $\mathrm{Me}_{4} \mathrm{tms}$ is characterized by one band at $277 \mathrm{~m} \mu,{ }^{(8)}$ this is not observed in $\mathrm{Me}_{4} \mathrm{bitt}^{2+}$ solutions, perhaps because its low intensity $(\epsilon=11,000)$ as compared with the strong absorptions of $\mathrm{Me}_{4} \mathrm{bitt}^{2+}$ in that region. (b) Neglecting the well known absorptions of $\mathrm{FeCl}_{4}{ }^{-(9)}$, it seems that all bitt ${ }^{2+}$ compounds display two bands in the u.v. region: (i) one between 270 and $280 \mathrm{~m} \mu$, which in the case of $I_{3}$ derivative seems to be obscured by the strong band of $I_{2}$ at $290 \mathrm{~m} \mu$, (ii) one more intense band near $240 \mathrm{~m} \mu$, present in all the compounds studied, which in the case of $\mathrm{FeCl}_{4}{ }^{-}$derivative should contain the absorption of the anion too, since the intensity in $\mathrm{Me}_{4}$ bitt $^{2+} 2 \mathrm{FeCl}_{4}^{-}$is too much higher than the one reported. ${ }^{(9)}$ Nevertheless, no interpretation of the origin of these two bands is still available.

It is interesting to establish that $\mathrm{Me}_{4} b_{i t t}{ }^{2+} \mathrm{Cu} X_{3}^{2-}$ can be synthetized in two alternative ways: (a) Reaction (1), above and (b) $\mathrm{Me}_{4} \mathrm{bitt}^{2+} 2 X^{-}+\mathrm{Cu}(\mathrm{I}) X \quad X=\mathrm{Cl}, \mathrm{Br}$ ). Further work is in progress about Raman spectroscopy of $\mathrm{Me}_{4}$ bitt $^{2+}$ haloderivatives, and possible reactions of type (b) with other metal halides.

Acknowledgement-We have to thank Dr. G. Contreras K., for his continuous interest and valuable advise on the development of this work.

\section{Instituto de Ouímica \\ Universidad de Concepción \\ Casilla 3-C}

Concepción Chile

HERNÁN CARBACHO $\mathrm{H}$. LUIS VICTORIANO L.

\section{REFERENCES}

1. J. Willemse and J. J. Steggerda, Chem. Commun. 1123 (1969).

2. V. Tamminen and E. Hjelt, Suomen Kemi, 23(B), 39 (1950).

3. P. T. Beurskens, W. P. J. H. Bosman and J. A. Cras, J. Cryst. Mol. Struct., 2 (1972).

4. H. Carbacho and L. Victoriano, to be published.

5. F. A. Cotton and J. A. McCleverty, Inorg. Chem., 3, 1398 (1964).

6. H. C. Brinkhoff and A. M. Grotens, Rec. Trav. Chim., 111, 252 (1971).

7. W. J. Geary, Coord. Chem. Rev., 7, 81 (1971).

8. G. D. Thorn and R. A. Ludwig, The Dithiocarbamates and Related Compounds, p. 74. Elsevier, New York (1962).

9. P. Day and C. K. Jorgensen, J. Chem. Soc., 6226 (1964).

J. inorg. nucl. Chem., 1975, Vol. 37, p. 1328. Pergamon Press. Printed in Great Britain

\title{
Some mixed metal tellurates
}

\section{(Received 31 October 1974)}

RECENTLY Brixner [1] has reported ordered perovskites of the type $A \mathrm{La} B \mathrm{WO}_{6}$ (where $A=\mathrm{Sr}, \mathrm{Ba} ; B=\mathrm{Li}, \mathrm{Na}, \mathrm{K}$ ). In the course of studies on the vibrational and luminescence spectra of compounds of this type in this laboratory [2] we tried to prepare the analogous tellurates.

Samples were prepared by usual techniques. Powder diffraction patterns were obtained on a Philips diffractometer using $\mathrm{CuK} \alpha$ radiation. The spectral measurements were performed as described elsewhere[2].

We found that $\mathrm{SrLaLiTeO}_{6}$ and $\mathrm{BaLaLiTeO}_{6}$ are ordered perovskites with lattice parameter $a=7.91$ and $8.04 \AA$, respectively. Surprisingly enough the corresponding compounds with $Y$ instead of $\mathrm{La}$ do not exist. Instead of this a.o. a garnet phase is formed with composition $\mathrm{Y}_{3} \mathrm{Li}_{3} \mathrm{Te}_{2} \mathrm{O}_{12}$. This compound can also be made as a single phase. Its lattice parameter amounts to $12 \cdot 24 \AA$.

Hexavalent uranium shows a green emission of medium intensity in the perovskites $\mathrm{SrLaLiTeO}_{6}$ and $\mathrm{BaLaLiTeO}_{6}$ and an intense yellow emission in the garnet $\mathrm{Y}_{3} \mathrm{Li}_{3} \mathrm{Te}_{2} \mathrm{O}_{12}$. This emission will be investigated further.

The vibrational spectra of these perovskite tellurates are similar to those of ordered perovskites $A_{2} B \mathrm{TeO}_{6}[2]$. All bands are somewhat broader than usually. This is probably due to the disorder of di-and tri-valent ions on the larger cation sites.

The vibrational spectra of the perovskites $A \mathrm{La} B \mathrm{WO}_{5}$ differ from those of the perovskites $A_{2} B W O_{6}[2]$. Not only are all bands broader, but also the $\nu_{2}$ mode is observed in the infrared spectrum (Fig. 1). This clearly indicates a deviation from inversion symmetry which is probably due to the mixed occupation of the larger cation sites. Note that in Sr-perovskites (e.g. $\mathrm{Sr}_{2} \mathrm{MgWO}_{6}[3]$ ) $\nu_{1}$ is not i.r.-active. The fact that in the corresponding tellurates the $\nu$ mode is not observed in the infrared spectrum may be due to spectral overlap, since the difference between the position of $\nu_{1}$ $\left(720 \mathrm{~cm}^{-1}\right.$ in Raman) and $v_{3}\left(680 \mathrm{~cm}^{-1}\right.$ in i.r. $)$ is small. The numerical values relate to $\mathrm{SrLaLiTeO}_{6}$.

The cation distribution in the garnet $\mathrm{Y}_{3} \mathrm{Li}_{3} \mathrm{Te}_{2} \mathrm{O}_{12}$ is most probably $\left\{\mathrm{Y}_{3}\right\}\left[\mathrm{Te}_{2}\right]\left(\mathrm{Li}_{3}\right) \mathrm{O}_{12}$ in view of the preference of $\mathrm{Te}^{6+}$ for 6 -coordination in oxides. We calculated the number of internal tellurate vibrations to be expected in the vibrational spectra assuming molecular $\mathrm{TeO}_{6}$ groups bound together by $\mathrm{Y}^{3+}$ and $\mathrm{Li}^{+}$ ions. The site symmetry of Te is $\mathrm{S}_{6}$, the space group $\operatorname{Ia} 3 d\left(\mathrm{O}_{h}{ }^{10}\right)$

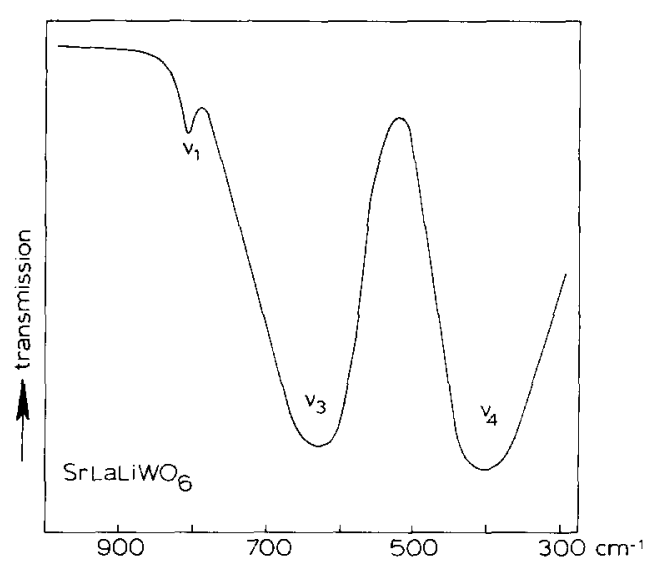

Fig. 1. I.R. spectrum of $\mathrm{SrLaLiWO}_{6}$ in the region $900-300 \mathrm{~cm}^{-1}$.

and there are eight $\mathrm{Te}^{6+}$ ions per primitive cell. As a consequence we expect two $\nu_{1}$ and four $\nu_{2}$ components in the Raman spectrum and three $\nu_{3}$ components in the i.r. spectrum. The exclusion principle is still valid. Our experimental results are as follows (values in $\mathrm{cm}^{-1}$ ): Raman: $750\left(\mathrm{w}, \nu_{1}\right) ; 730\left(\mathrm{~s}, \nu_{1}\right) ; 650,600,530$ and 515 (all weak, $\left.\nu_{2}\right) ; 467$ and $432\left(\mathrm{~m}, v_{\mathrm{s}}\right)$. i.r.: $710\left(\mathrm{~m}, \nu_{3}\right) ; 665$ (s, br, $\left.\nu_{3}\right) ; 630\left(\mathrm{~m}, \nu_{3}\right) ; 590\left(\mathrm{~s}, \nu_{3}\right) ; 490\left(\mathrm{~s}, \nu_{4}\right) ; 465\left(\mathrm{~m}, \nu_{4}\right) ; \approx 420\left(\mathrm{~s}, \mathrm{br}, \nu_{4}\right)$.

Our predictions are correct for the Raman spectrum; in the infrared spectrum there are more bands in the $\nu_{3}$ region than expected. Perhaps there is a deviation from the ideal cation distribution. This point is under investigation.

Physical Laboratory

State University

DENISE KROL

Sorbonnelaan 4

G. BLASSE

Utrecht

The Netherlands

\section{REFERENCES}

1. L. H. Brixner, Mat. Res. Bull. 9, 1041 (1974).

2. G. Blasse and A. F. Corsmit, J. Solid State Chem. 6, 513 (1973).

3. G. Blasse, J. Inorg. Nucl. Chem., in press. 